\title{
Introduction
}

\section{Cognitive Psychology and Survey Methodology: Nurturing the Continuing Dialogue between Disciplines}

\author{
ROBERT F. BELLI ${ }^{1}$, FREDERICK G. CONRAD ${ }^{2}$ \\ and DANIEL B. WRIGHT ${ }^{3}$ \\ ${ }^{1}$ University of Nebraska-Lincoln, USA \\ ${ }^{2}$ University of Michigan, USA \\ ${ }^{3}$ University of Sussex, $U K$
}

For quite some time, survey researchers have sought to understand the causes of response errors, that is the difference between what respondents report and the truth of their circumstances (O'Muircheartaigh, 1997). Within the past 20 years, a dialogue has emerged between cognitive psychologists and survey researchers to explore the role that cognition plays in response errors (Jabine, Straf, Tanur, \& Tourangeau, 1984; Jobe \& Mingay, 1991). The dialogue has been known as the cognitive aspects of survey methodology (CASM) movement. Of course, to survey researchers, the aim is to reduce response errors. By adopting perspectives and methods from cognitive psychology, survey researchers have acquired a fuller understanding of the role of cognitive processes in question answering (Tourangeau, Rips, \& Rasinski, 2000), and on how to better control and reduce response errors (Belli, Shay, \& Stafford, 2001; Willis, 2005). But for cognitive psychologists, their aim has been to acquire new research findings that will advance cognitive theory. Recently, some researchers have been expressing frustration on the apparent lack of progress on this front (Tanur, 1999; Tourangeau et al., 2000, pp. 335-340; Wright \& Loftus, 1998). For this dialogue between cognitive psychology and survey methodology to be a healthy and vibrant one, both disciplines must see the relationship as being worthwhile.

In this special issue, we have assembled research papers that focus on cognitive processes within the applied arena of survey interviewing and data collection. The specific papers that appear were submitted in response to a call for papers (Belli, 2005) and a subsequent editorial process of peer review and revision. Importantly, our work is not yet finished. Following this special issue, additional peer-reviewed papers that had been submitted to the call will be published in regular issues of this journal, as there were far too many excellent papers than could be accommodated in one special issue due to limited journal space and editorial time.

The papers in this issue concentrate on three areas that are relevant to CASM. The first two papers, by Ongena and Dijkstra (2007, this issue), and by Conrad, Schober, and Coiner (2007, this issue), explore the role of communication and interaction in survey response. The middle two papers, by Galesic and Tourangeau (2007, this issue), and by Chessa and 
Holleman (2007, this issue), focus on context effects produced by the formal features of questionnaires. Finally, the last three papers that are authored by van der Vaart and Glasner (2007, this issue), by Stocké and Stark (2007, this issue) and by Brown, Williams, Barker, and Galambos (2007, this issue), each investigate factors that impact on the quality of retrospective reports. Such partitioning, however, tells us little about what these papers are fundamentally about, especially with regard to cognition. Each paper in its own way illustrates the challenges of investigating cognition in real world environments because of multiple interacting variables, as discussed by Schwarz (2007, this issue).

In terms of the different aims of survey researchers and cognitive psychologists, it is noteworthy that the purpose of these papers is either to understand question answering, or to demonstrate how response errors can be reduced, but not to advance cognitive theory. The explicit testing of a cognitive model only appears in Chessa and Holleman (2007, this issue) as they seek to explain context effects associated with question wording. It would be a mistake, however, to characterise only the Chessa and Holleman piece as one in which the survey context is used as a natural laboratory to confirm whether cognitive models derived from basic research will be able to account for behaviour in an applied context. All of these papers provide insights into the operation of cognitive processes whenever individuals are asked to report their attitudes or behaviours in real world settings.

Simply summarising the specific content of each of the papers in this special issue illustrates the insights on cognitive processes that they reveal. Ongena and Dijkstra seek to model the complex verbal interactions that occur between interviewers and respondents that involve both cognitive processes that are internal to each of the survey participants, and the overt expressions of these processes via spoken language. Similar to Ongena and Dijkstra, Conrad, Schober, and Coiner also focus on the role of collaborative communication in producing survey responses, but instead of examining interaction between humans, they explore whether designing web survey questionnaires to emulate this interaction-in particular allowing the computer to clarify the questions-can improve response quality. The paper by Galesic and Tourangeau examines the role of framing in leading to context effects on reports of the subjective frequency of events, and on reports of which types of events are considered as bothersome and sexually harassing. The cognitive mechanisms they invoke to explain their observed response effects include inferences of communicative intent and memory priming. In their implementation of the memory chain model, Chessa and Holleman illustrate how response time distributions vary on whether connotatively stronger or weaker attitude reports are being requested. With requests for stronger attitude reports, additional judgement and retrieval steps are modeled, and these additional processes translate into increased response times. van der Vaart and Glasner used a timeline methodology, hypothesised to promote the use of cues inherent in the structure of autobiographical knowledge, to improve retrospective reporting accuracy. Stocké and Stark provide arguments and evidence that motivational factors, including the desire to be accurate and to receive social approval, play a pivotal role alongside cognitive processes as determinants of the accuracy of retrospective reports. Finally, Brown, Williams, Barker, and Galambos discover that when deriving retrospective reports, the cognitive strategies that are used for activities are generally different than those used for emotions, and that reports of emotions can be reasonably accurate. Whew!

Taken as a whole, these papers provide direction as to how studying cognitive processing within the survey context can advance cognitive theory. Observing the interaction of cognition, communication and other processes within social encounters has the potential to advance cognitive theory which has largely been developed by isolating cognition from the 
social environment. Further, the survey context can be used as a real world test bed by which cognitive theories can be evaluated (Loftus, Feinberg, \& Tanur, 1985). Moreover, for example, discovering the cognitive strategies that are used in providing frequency reports (Brown, 1995; Conrad, Brown, \& Dashen, 2003), and determining the properties that lead persons to interact with inanimate objects as if they were human actors (Dahlback, Jonsson, \& Ahrenberg, 1993; Kennedy, Wilkes, Elder, \& Murray, 1988), are lively topics within the field of cognitive psychology in which the interdisciplinary area of cognition and survey measurement is a contributor.

Perhaps some of the expressed frustration with the apparent lack in advancing cognitive theory has been due to overly optimistic expectations on how quickly such advances would become apparent. As illustrated by some of the papers in this issue, the manner in which cognition operates in the real world of social encounters is complicated and challenging, with many interacting variables. Thus, truly collaborative efforts from experts in both cognitive psychology and survey methodology are needed to reap as much benefit as possible for both fields. Although the CASM movement has grown considerably since its inception some 20 years ago, too much of this research has been conducted outside the purview of most cognitive psychologists, that is those experts who are best versed in cognitive theory and who can see most clearly not only the potential relevance of CASM research in advancing cognitive theory, but also the cognitive processes that impact on response quality. Our hope is that this special issue will encourage a more intense dialogue between CASM-oriented researchers and applied cognitive psychologists that would be realised by an increased number of CASM-oriented publications in this journal and papers presented at the Society for Applied Research in Memory and Cognition (SARMAC) international conferences. Applied Cognitive Psychology and SARMAC stand ready to help nurture a stronger relationship between cognitive psychologists and survey methodologists that will benefit both fields.

\section{REFERENCES}

Belli, R. F. (2005). Editorial: Announcing a special issue on the cognitive aspects of survey methodology. Applied Cognitive Psychology, 19, 245-247.

Belli, R. F., Shay, W. L., \& Stafford, F. P. (2001). Event history calendars and question list surveys: A direct comparison of interviewing methods. Public Opinion Quarterly, 65, 45-74.

Brown, N. R. (1995). Estimation strategies and the judgment of event frequency. Journal of Experimental Psychology: Learning, Memory, and Cognition, 21, 1539-1553.

Brown, N. R., Williams, R. L., Barker, E. T., \& Galambos, N. L. (2007). Estimating frequencies of emotions and actions: A web-based diary study. Applied Cognitive Psychology, 21, 259-276 (this issue). DOI: $10.1002 /$ acp.1303

Chessa, A. G., \& Holleman, B. C. (2007). Answering attitudinal questions: Modelling the response process underlying contrastive questions. Applied Cognitive Psychology, 21, 203-225 (this issue). DOI: $10.1002 / a c p .1337$

Conrad, F. G., Brown, N. R., \& Dashen, M. (2003). Estimating the frequency of events from unnatural categories. Memory \& Cognition, 31, 552-562.

Conrad, F. G., Schober, M. F., \& Coiner, T. (2007). Bringing features of human dialogue to web surveys. Applied Cognitive Psychology, 21, 165-187 (this issue). DOI: 10.1002/acp.1335

Dahlback, N., Jonsson, A., \& Ahrenberg, L. (1993). Wizard of oz studies: Why and how. Knowledge-Based Systems, 6, 258-266.

Galesic, M., \& Tourangeau, R. (2007). What is sexual harassment? It depends on who asks! Framing effects on survey responses. Applied Cognitive Psychology, 21, 189-202 (this issue). DOI: 10.1002/acp.1336 
Jabine, T. B., Straf, M. L., Tanur, J. M., \& Tourangeau, R. (Eds.). (1984). Cognitive aspects of survey methodology: Building a bridge between disciplines. Washington, DC: National Academy Press.

Jobe, J. B., \& Mingay, D. J. (1991). Cognition and survey measurement: History and overview. Applied Cognitive Psychology, 5, 175-192.

Kennedy, A., Wilkes, A., Elder, L., \& Murray, W. S. (1988). Dialog with machines. Cognition, 30, $37-72$.

Loftus, E. F., Fienberg, S. E., \& Tanur, J. M. (1985). Cognitive psychology meets the national survey. American Psychologist, 40, 175-180.

O’Muircheartaigh, C. (1997). Measurement error in surveys: A historical perspective. In L. Lyberg, P. Biemer, M. Collins, E. de Leeuw, C. Dippo, N. Schwartz, \& D. Trewin (Eds.), Survey measurement and process quality (pp. 1-25). New York: Wiley.

Ongena, Y. P., \& Dijkstra, W. (2007). A model of cognitive processes and conversational priniciples in survey interview interaction. Applied Cognitive Psychology, 21, 145-163 (this issue). DOI: 10.1002/acp.1334

Schwarz, N. (2007). Cognitive aspects of survey methodology. Applied Cognitive Psychology, 21, (this issue). DOI: 10.1002/acp.1340

Stocké, V., \& Stark, T. (2007). Political involvement and memory failure as interdependent determinants of vote overreporting. Applied Cognitive Psychology, 21, 239-257 (this issue). DOI: $10.1002 /$ acp. 1339

Tanur, J. M. (1999). Looking backwards and forwards at the CASM movement. In M. G. Sirken, D. J. Herrmann, S. Schecter, N. Schewarz, J. M. Tanur, \& R. Tourangeau (Eds.), Cognition and survey research (pp. 13-19). New York: Wiley.

Tourangeau, R., Rips, L. J., \& Rasinski, K. (2000). The psychology of survey response. Cambridge: Cambridge University Press.

van der Vaart, W., \& Glasner, T. (2007). Applying a timeline as a recall aid in a telephone survey: A record check study. Applied Cognitive Psychology, 21, 227-238 (this issue). DOI: 10.1002/ acp. 1338

Willis, G. B. (2005). Cognitive interviewing: A tool for improving questionnaire design. Thousand Oaks, CA: Sage.

Wright, D. B., \& Loftus, E. F. (1998). How memory research can benefit from CASM. Memory, 6, $467-474$. 